\title{
The Importance Of A Good Business Plan
}

Les Nunn, University of Southern Indiana, USA

Brian McGuire, University of Southern Indiana, USA

\begin{abstract}
The business plan is the product of a strategic thinking or planning process. The strategic direction developed in that process can then be communicated in the form of a business plan to lenders, potential investors and associates within your company. The development of a strategic direction is a critical step for your company. It allows your business to leverage the knowledge and competence of its management team, staff and advisors to develop a strategic direction for the organization that will lead to its best chance for success. This gives you an opportunity to use the advising team you have put together.
\end{abstract}

\section{INTRODUCTION}

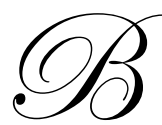

to get there!

efore starting your business, know where you are going. As the old saying goes, "there are a lot of people who have climbed the ladder of success only to find on reaching the top that it was leaning against the wrong tree." Know where you are going with your endeavor and know how you are going

Keep in mind the purposes of a business plan. On the one hand, it is written to guide the business owner in how to develop and operate the business. A business plan becomes the plan of operating the business. On the other hand, it is written with the intention of attracting a lender or investor to finance the start-up or next phase of the business.

Lenders and investors want to understand their level of risk and what they will get in the way of returns on their investment. Be prepared to address all issues honestly and intelligently to best communicate to lenders/investors and yourself. Be up front about the risks and the strategies you are implementing to mitigate those risks. You should do this analysis and plan for your own benefit, even if you do not need a lender or investor.

The degree of planning will depend, in part, on the size of the enterprise. The time put into the plan will greatly impact your chance for success. There are four basic types of business planning: (1) strategy, (2) operations, (3) financial budgeting, and (4) forecasting. While large companies may have four separate plans, smaller organizations may create one plan that contains a blend of the elements of all four.

\section{THE BUSINESS PLAN FORMAT}

Your business plan should include the following sections: a good business plan includes sections on (1) Title Page, (2) Table of Contents, (3) Executive Summary, (4) Business Description, (5) Management (6) Market and Business Analysis, (7) Business and Market Development, (8) Marketing and Sales, (9) Financial Data, (10) Application of Funds, and (11) an Appendix. In addition, it may take anywhere from two weeks to six months to complete the planning process. However, it is essential that you do this planning. After careful planning, you might find out that your dream business just will not work out financially. It is so much better to learn before you lose your million dollars that something will not work than to borrow money, put in your life savings and then go broke (losing everything you have worked for in the process). 
Obtaining the needed financing to start, operate and/or expand your business can come from lenders and investors. Your business plan should address their needs as well as your own operational purposes. Even if it is not necessary for you to borrow funds or take in an investor, you should plan and develop your business to be making money. If you lose money each year, it is only a question of time before you go out of business, right? So write your plan with "you the operator" in mind, your banker or other lender in mind and you and/or your business partner in mind.

Although the Management and Executive Summary sections were viewed as the most important, all the sections were considered key. Characteristics of a good plan, according to those surveyed, included that it be wellwritten, organized into sections and include detailed financial projections. Whether the document was bound, contained graphs and tables, had color graphs and pictures, or details referenced in the plan were not critical to the plan's quality. Finally, those surveyed felt the business plan played an important role in stimulating initial interest, and even more importantly, in deciding whether or not to meet with management.

Once again, keep in mind the purpose of a business plan. On the one hand, it is written to guide the owner in how to develop and operate the business. A business plan becomes "the plan" for operating the business. On the other hand, it is written with the intention of attracting investors and/or lenders to finance the start-up or next phase of the business. From this perspective, it is important to establish what has been done to date and what is being done today to lay the groundwork for your success. Then, you can lay out the plan for the future.

You, the owner (as well as your potential investors and lenders), will understand the level of risk associated with this business venture, as well as what can be anticipated in the way of financial and other returns on the investment to be made. Be prepared to address the issues honestly and intelligently to best communicate your goals and aspirations. Be up front about the risks and the strategies you are implementing to mitigate those risks.

You must plan your venture well! There are four basic types of business planning and these will be discussed in more detail a little later: strategic, operational, financial budgeting, and forecasting. While large companies may have four separate plans (one for each of the types of plans), you can do it all in one plan which contains elements of all four. While your plan will show you recognize the business opportunities that are out there, it must also convince the investor/lender that you have a valid, workable plan to control and minimize that risk. In addition, determine how big your plan should be. For example, the plan itself should run about 30 pages or so in length. However, with the appendix and attachments, it will probably be as much as 100 pages. It should be written so that a potential lender/investor can easily find what he or she wants to see.

Investors/Lenders are your target market when writing a business plan. How many plans does the average banker see a month? A recent informal survey done by a graduate students in the Masters of Business Administration program at the University of Southern Indiana found that, of those surveyed, over half reviewed more than fifty business plans a month. Ninety-four percent of those surveyed said they did not have any interest in seeing business plans submitted in an electronic form. Forty-five percent indicated they would feel comfortable with a professional firm helping an entrepreneur prepare his/her plan.

While all sections were considered important by the lenders, the Management and Executive Summary sections were viewed as the most important. Characteristics of a good plan were that it was well-written, organized into sections, and included detailed financial projections. Whether the document was bound, contained graphs and tables, had color graphs and pictures, or details referenced in the plan were not seen nearly as important. Finally, those surveyed felt the business plan played an important role in stimulating initial interest, and even more importantly, in deciding to meet with the management team of the entrepreneurs submitting the plan.

As most presentations on anything, be sure you cover the "five w's" (i.e., who, what, when, where, and why) of your proposed business venture. Tell them briefly what you are going to tell them, tell them in some detail what you want them to know, and then tell them at the end what you told them. Have data in your Appendix to verify your projections and conclusions presented. Stating it simply, you should organize your plan so that it facilitates the prospective investor/lender's review of your plan. 


\section{- $\quad$ Title Page}

Your business plan must have a title or cover page. This page should include your company name, logo, month and year formed, the name of the point person in the financing of the business (including his/her address and phone number) fax number for the business, and, if you have it, your website address. If you are worried about someone "stealing" your business ideas, include a non-disclosure statement on the cover page that is to be signed by the prospective lender/investor to which you are giving the plan (the non-disclosure statement will be explained in a later section).

If you are going to be showing copies of your plan to a number of people, it is suggested that you put a control number on each copy. Then, keep a master list of who has which copy of the plan. That way you can keep track of who has copies of your plan. In addition, do not forget to get the copies back when people are finished looking at them.

\section{- $\quad$ Table of Contents}

Put your business plan together to serve the needs of potential investor/lenders. Remember that the person reading your plan might not read it in the same order in which you have written it. Some lenders may be interested in reading one part of the plan first and forming their initial decision of whether or not to read further based on that one section alone.

Therefore, it should be organized to facilitate the reader's review of the information you have included in the plan. In addition, include a table of contents and have separators (tabs) for each section of the plan.

It cannot be impressed too much how important it is to tab each section and the attachments in the appendix. While it is true that another purpose of the plan is to guide you in the development and operations of your business, you know the plan and its attachments because you wrote them. Nevertheless, having sections denoted with a tab can help those reading the plan find what they are looking for as well as help you find what you need quickly. Once again, make it easy for your investor/lender to review your plan. The easier it is for them to use, the better impression they will have of you and your company!

\section{- $\quad$ Executive Summary}

The Executive Summary is a very brief overview of the plan and your business model that is intended to capture the reader's interest. This part of the plan is generally at most two pages long. A "rule of thumb" is the shorter the better. But it must be very well written! Remember that those people reading your business plan may not know anything at all about your industry or what it takes to run a successful business. You must make sure everything you say in your plan will be easily understood by all who read it. This is especially true in the Executive Summary section.

You must spend time on this summary, which should be able to tell the reader in just a couple of minutes what it is you want to do, how you want to do it, and why you want to do it that way. Practice this part well. Get help from other people on this section. Have them read what you have written and see if it "grabs" their attention. Remember, when you talk to a banker or investor, you will have only a couple of minutes to tell him/her about your proposed business venture, and make sure you do this well.

The Executive Overview should touch on each part of the business plan. The purpose of this part is to generate enough interest in the reader that he/she will want to read on further and study your plan. This part provides the initial opportunity to explain the amount of funds required and the purpose of securing those funds.

\section{- $\quad$ Business Description}

Mission: In the mission section, you should state what the mission or main purpose of your business is. Include a list of core values (the things you believe essential to your business success) that you will follow in operating your 
business. Remember, nobody will understand the mission of your company as well as yourself. You need to explain these things clearly and succinctly. Do not worry about using fancy legal words here. Simply state it in your own words, but write it in such a way that the reader can see your passion for the business you are creating. The mission and core values must be clear and stress the few things you think are vital to your new business and that will set it apart from all other businesses.

Facilities: This is the appropriate section to list and describe your present facilities. Include location, size, purpose and utilization. An easy to understand drawing of your property would be helpful. This could be a date or a volume of business point, but explain how you will know when the new facility will be added. In addition, paint an accurate (but complimentary) picture of what your place looks like or will look like. You should be brief, but descriptive, and explain how these facilities will be used in the operation of your business. Forecast when you might need additional facilities; explaining what factors will indicate the appropriate time for the additions and how you intend to build and finance them. Go briefly into the anticipated financial gain these additions will bring you, but note that this will be covered in detail in your financial data section (remember to give the Tab number where the investor can immediately find this information.

Tell why you want to build or buy instead of leasing, if that is the case. If the contrary is true, tell why you want to lease instead of building or buying. What, if any, of your business work will you subcontract out to others and why?

Business Strategy: Topic areas you will want to consider covering in this section include the products and/or services you will provide, value propositions, organizational structure, alliances and relationships with other businesses (networking). Your strategy section should include a discussion of the opportunities on which your company can capitalize. Explain how you intend to use each of the opportunities discussed, and explain your point of leverage. Discuss alternatives that are also available.

List the products and services you intend to offer to your customers. Explain at what target market you are aiming, and discuss the possible problems your company will solve for potential customers. In addition, discuss alternative markets and the size of those markets, and address possible products or services to be added to your business in the future (including what you will use as signals regarding when it is time to add them). Furthermore, discuss how your customers could perceive your products and services.

You should also address the various values you will offer to your customers, which could include what you will do for your customers to help them and why this is important to them. You could also address the areas that you see as the most important things that you will do for customers and why these are important. In addition, you might discuss how your products and services will differ from those of your competitors, and explain each difference (and tell why it is important for your customers to have these differences).

One of the keys to a successful business is your ability to network. This involves creating relationships (alliances) with other businesses that can help you do your job better and with those who can feed customers to your business. Look for those other businesses which, while not competing directly with what you do, can nevertheless serve people who would benefit from your business. By joining with these "feeder" businesses you are networking with, you can "piggy back" your business onto what they are already doing.

For example, tell in this part of your plan that you might have a clinic or seminar featuring a well-known expert who will also promote your product or service. In so doing, you gain immediate credibility with the audience. They obviously think this expert is worthy of their time or they would not be there to hear him/her. When the expert compliments you, some of his/her expertise rubs off on you. Your logo gets your name and company image before the crowd. Your business cards and flyers have the additional "blessing" from the expert who is the center of the show. It is a win-win proposition for you and it did not cost you any money to do it (and make sure your phone number is easy to find on your promotional materials, including your business cards and flyers).

In your plan, show a diagram of whom you will network with. They may be suppliers, customers, or others in the industry. Explain your relationship with each of them and show how you will use your happy customers to 
"spread the good word" to others about your business. Describe any joint marketing agreements you plan to enter into with your networking people, and discuss how you will jointly develop your business with them developing theirs.

When you network with someone, you are tying your reputation to his or hers. Therefore, make sure you explain how you will carefully select good quality people to network with and show how it will help (and not hurt) you and your business.

\section{- $\quad$ Management}

You should have a separate section on management and showcase the individuals who make up your management team and how they work together. Investors and lenders place a significant interest on your management team. You should list the people in key positions that have been filed and provide a brief biography for each of the people, giving their qualifications for the job and show what they bring to the job.

If you have not filled all of your management positions, describe the skill levels and personality traits you are looking for in the job applicants for those unfilled positions. You should list any outside advisors you may have lined up. These would include your accountant, lawyer, insurance agent and general business advisors. If you are setting up a corporation, list your board of directors. Resumes of all the in-house and outside managers and advisors can be placed in your Appendix section.

\section{- $\quad$ Market and Business Analysis}

This is one of the most crucial sections of your plan. Begin with the development of an understanding of the current state of your business venture. Tell how you have the company organized now and what you are doing in your present business. It helps the lender/investor to get an understanding of how your company is today. You should go through a SWOT (i.e., Strengths, Weaknesses, Opportunities, and Threats), as doing this analysis can really help you (and others) to take a critical and objective look at your business.

Strengths: You should list and briefly describe each major and important part of business in which you think your company is strong. Go through all that you currently have going on or plan to do in the future in your business activities and pull out what you do well, as these are your strengths.

Weaknesses: Objectively admit where you need help to become stronger. For example, discuss where you are good with people and marketing, but then mention that you are not very skilled in the accounting and bookkeeping departments (be realistic and do not be afraid of telling your investor these thing). If you investor knows you very well, he or she probably knows these weaknesses about you anyway, and admitting the weaknesses is a sign of strength (because it shows you have done a careful self-analysis and recognize the areas where you need help). In addition, you want to tell what you are going to do to overcome those weaknesses.

Opportunities: These are where you can really take advantage of a void or vacuum in the industry - where there is a need that you can fill. List these opportunities and describe how you can take advantage of those opportunities.

Threats: Consider what could go wrong with your plan to become successful in your business. For example, it may that the economy of your local community is based on one major employer. If that company terminates workers, then the economy of the whole community could turn bad. In addition, threats could include competitors who are already in business in your area, and they might have most of the good clients and you have slim pickings on what is left.

Whatever might be the threats to your business being successful, you must identify them and explain how you will overcome them and make your business profitable. You should notice that the "Strengths" and "Weaknesses" are internal. That means they are things about you and your company. On the other hand, "Opportunities" and "Threats" exist in the external environment, as they relate to things outside your company. 
The last thing to do in this section is to make some comparisons. First of all, compare your strengths to the opportunities, and demonstrate how (with your strengths) you can take advantage of the opportunities. In addition, compare your strengths to the threats, and show how you will use your strengths to overcome the outside threats to your company's success. Thirdly, compare the weaknesses in your company to the opportunities (explaining how you will overcome those weaknesses by taking advantage of the opportunities) and lastly, the weaknesses to the threats facing your company. You should include a discussion as to how you will overcome those weaknesses and still meet and surmount the threats.

This exercise may seem difficult at first. But once you get into it, you will see that it can become fun to look at your business in a "what if" kind of mode. By using these comparisons properly, you can show that you have developed specific strategies that will help your company to move forward successfully and profitably. In addition, there are a couple of more things you should consider in this section, and they relate to competitors. While you may have mentioned your competitors in the SWOT analysis, you need to look at them more carefully.

Finally, address the topic of who your competitors will be, and what it is they are doing (and how are they doing it). In addition, you should discuss how your business approach will differ from theirs, and address what the chances are that someone else will open a new business that could compete with your business.

\section{- $\quad$ Business and Market Development}

The proposed location of your business should be discussed. Explain whether you will build or buy and tell why. Another item to discuss is a review of the labor market, both cost and availability, and how the availability of the experience pool and skills will be adequate to meet the needs of your proposed business. List all trends in the geographic area concerning past labor and management relations. Describe how any expansion requirements could be a factor in the decision to locate in a specific site. Will your product or service process require unique or costly resources? Describe the results of large or small focus groups you have worked with and what their opinions were about the potential success of your business. Include any photos to better display and convince lenders/investors of the accuracy of your business plan.

We suggest that for this part of your plan, you should start with the broad picture and work your way down to the narrow view of how you will operate your business. In addition, you should explain the characteristics of your market. For example, discuss what you see as the future trends for your industry being in your part of the industry and your market area, and address what the typical customer for your type of business looks for in products and services. If there are any surveys that have been done on this topic, list them as a footnote, as this will add credibility to what you are saying.

Once you have explained this in your business plan, tell what you are going to do in your business, and give enough detail that the uneducated reader can easily and clearly understand what it is you plan to do, and show how you plan to get some of the business that is out there. Demonstrate how you can get enough of that customer base to make your own business profitable, and give estimates of what percentage of the market you think you can realistically get. By using a separate tab in the Appendix (or as a footnote to this portion of your business plan), explain in some detail just how you determined the total potential customer base and how you determined what portion of that customer base you can and will get to become your customers.

With every potential success comes a lot of risk. You must help your investor or banker see that you understand this risk. Looking at the risk side of it has two parts. One is the correct analysis of the risk for failure, and the other is what your plan is for minimizing and controlling that risk. Treat the major risks separately. Describe them separately and then treat each one separately in your plan to control the risk as you describe it here.

It is important to demonstrate just how the services or products you will offer will be used in your business. List all products and services you will offer and, with some detail, explain how you will do it. Any brochures, flyers, diagrams and other material you have will come in very handy here. You should reference them in the plan and then attach them in the Appendix. In addition, describe from a timeline standpoint when each product or service will be started. Show in detail how your services will be different from those of your competitors. This is your 
chance to totally convince the lender/investor why your product and/or services will have greater buyer significance than your competition. Share how your products and services are unique and provide a value added component for your customer.

You should explain the labor market for hiring the people you need to do the work. For example, address the trends in your community for the labor pool, and if there will be an anticipated shortage of skilled labor, show how you will overcome this problem. In addition, discuss what (if any) of your business work will you subcontract out to others.

Finally, address how you will know what your customers need (and how they view your company), and what customer satisfaction surveys will you use (and how will you use them) if you decide to use satisfaction surveys. You should also develop an effective customer plan that permits customers to reach you any time they need to, which could include: (1) what will be your involvement with the Internet; (2) how will you handle an unhappy customer; and (3) how will you use customer feedback to shape your near future operations?

\section{- $\quad$ Marketing and Sales}

In the previous sections, you have shown what the potential customer base (market) is and how you will operate your business to service the customers you get. In this section, you want to show how you will attract new customers and describe the entire marketing effort of your company. Share your sales strategy with the lender/investor in detail. In addition, you should describe all advertising (mail, flyers, networking, radio, television, Internet, etc.) that you will be using, and in the Appendix, include copies of all sales brochures you will use. Discuss promotional and public relations approaches you will use, and describe how customers will perceive your company. Furthermore, you should address how you will use small focus groups to give you direction of what to do, including (1) what other market research efforts will you use and how; (2) will you joint venture projects with others; and (3) if so, why and who will you work with?

You should be careful how you involve yourself in all of this. One of the biggest mistakes new entrepreneurs make is that they try to do everything themselves. This is impossible. If you are doing 20 things at once, you do not have the time or energy to keep an eye on the overall project to see how things are going. You must keep enough free time for yourself to see what is and is not happening in your business. As stated before, you must have your goals in mind and be working steadily towards them. Show how you will use other people to help you. While you might not have enough money to hire people to do these things for you, you may be able to work out trades to get the work done.

Your marketing objective is to create the maximum amount of new customers in a short period of time. You may have to start out as a "no-frills" operation, but explain how this will grow in your marketing program. You should keep in mind that there are others providing products and services to the same people who hopefully will be your customers. For example, discuss how you can tie your business to those other businesses, and explain all of these types of marketing approaches you plan to use. Will you send out a monthly newsletter to people (if so, then tell about this), and what other ideas are you going to use to attract and keep new business?

\section{- $\quad$ Financial Data}

The financial data section is fairly detailed, and yet some investors will state that it is the most critical of all parts of the Business Plan. Therefore, you must show that you have done your homework and know what your business will and will not do from a financial standpoint. While the types of financial projections necessary to be included will be covered in detail later, a general overview of them would be helpful now.

Profit and Loss Statement: You might want to address: (1) how can I know how many customers I will have and when I will get them; (2) how can I know what my utilities will cost; and (3) what will the cost of insurance be? Although you may not know exactly what these costs and projected incomes will be, you had better have a pretty good idea before you start out by risking your money or someone else's money on your business venture. However, it is not really that difficult to figure out, and you must do the financial section with great care. This statement will 
tell you whether your business can be profitable or not. If it is going to be a money loser the way you have it planned, then you had better change your plan so that it can become profitable.

You should work out the information yourself as best you can. For example, if you are breeding horses, then you know better than an accountant how much hay and grain a horse will eat in January as compared to June when the pasture is green. You should also know what it costs for a farrier to do a trim or set shoes on a horse. You must call around to insurance agents to see what the insurance premiums will be from different companies to provide you with the coverage you should have. You can call the local newspaper and radio/television stations to see how much advertising costs. You should know how much you would have to pay to get a decent stable hand to clean stalls. A telephone to your local utility company can help you project what it will cost for electricity and gas utilities per month in the summer and in the winter.

It is amazing how much information you can find out just by making a few phone calls. But first you must know what types of expenses you are likely to have. To help you with this, the next chapters give you some things to think about in categories of income and expenses. We encourage you to make lists for yourself of anticipated income and expense categories and then figure out what each one will cost you or bring in how much income for you. Then, after you have done as much as you can, call up your accountant and go to him or her with what you have. You can learn and understand better what the accountant tells you if you have first done some of the work yourself.

The accountant will help you as to what other types of incomes and expenses you might anticipate that you have not thought about. It is important to develop a good relationship with your accountant from the beginning. You may change accountants later, but if you start the business with an accountant involved, it certainly increases your chances of success from the get-go. After you follow these subsequent steps, you should be able to do the information you need to include in this Financial Data portion of your Business Plan.

A three-year financial income statement (profit and loss) spreadsheet summary is essential. You may compute a five-year plan also, but the rapid rate of changes in the world today usually in industry usually causes a projection of more than three years to not be received with much confidence. In addition to the income statement spreadsheet, it is highly advisable to include a source of projected revenues. Sources of the gross revenues by specific product/service are important to give credence to the lenders or investors reviewing the business plan. Include assumptions of why you believe the revenue streams will be generated, thereby giving stability to your projected income spreadsheet. Include comments as to why any new equipment may reduce part of your overall cost structure and increase your efficiency. Explain also if volume discounts have been used in the projections. Tell if you feel the projected gross margin will become better or worse over time.

You should demonstrate how much market penetration is being considered by you with these initial projections, and comment on whether any increases for cost of goods sold have been included after the initial year of operation. Always refer back to appropriate sections of your business plan like marketing and industry analysis to support how you feel the financial projections will be credible. Certainly comment on any larger items in the Income Statement spreadsheet, especially if they are larger than normal the initial year of a new operation. The projections will be better received if shown by month for the first year and then by yearly calculations thereafter.

An income statement will always have a cost of goods sold, unless it's a business like a lawyer, accountant, financial advisor or other professional service type organization. These types of service organizations generally have only fixed cost in nature. An income statement is a picture of company operations over a given period of time. A bank or investor for a new operation always prefers a monthly statement. The primary benchmarks are gross profit and net profit. Gross profit measures what remains after direct expenses, such as direct labor and materials, which are subtracted from total revenue. Net profit measures what remains after general operating expenses are subtracted from the gross profit described previous.

Balance Sheet: Projected balance sheets are important so as to show all current assets, all liabilities and owners equity. The balance sheet could also be shown by month the first year, but especially must be shown on a yearly basis. The balance sheet is sometimes not given very much attention, since the income statement is held in such 
high esteem. However, to a banker, the balance sheet is most important. The balance sheet describes the financial health of the company. The balance sheet is divided into assets (i.e., what the business owns), liabilities (i.e., what the business owes to those who supplied the funds to buy the assets, known as the creditors), and net worth (i.e., the value of the company to the owners). In a sense, it is "what you own" minus "what you owe" is equal to "what your worth."

Income Statement: The financial operating cycle is simply that the business assets generate sales. These sales hopefully generate net profits. The use of future profits is to pay for new assets, pay off debt and pay out earnings to owners. Of course, hopefully some net profits are left after the above three things occur. The residual amount left is then kept in the business and known as retained earnings. There are many operating ratios for a business owner to look at and a good accountant or CPA can help to provide very in-depth analysis of a business plan financial segment. The more capital that is required and as higher capital requirements take shape, a strong suggestion is for an owner to seek the help of a qualified CPA for help to complete a more detailed and elaborate financial business plan.

Managing the income statement is very critical for survival of a new business or new division of a company. A breakeven analysis would be very helpful to investors to demonstrate that you understand all your fixed costs in relation to your selling price less all variable cost to give the business its breakeven level to be achieved. In addition, "fixed costs" are those costs that you must pay whether you have any income or not. Fixed cost are expenses that do not vary with sales, they are incurred regardless of the sales level. They include such things as insurance, utilities, truck payments, etc.

The "breakeven point" is where income exactly covers all expenses and no profit or loss is generated. "Variable costs" are the expenses that vary directly with sales and are only incurred as sales are made. The "contribution margin" is the amount of revenue left over after variable costs are all are paid. This amount left goes to cover fixed cost being incurred.

Cash Flow Statement: Finally, (but often considered the most important), you must prepare the Statement of Cash Flows. Cash flow is considered "king," and no matter how much your net worth is on "paper," you can only stay in business if you have the cash to pay your bills. Cash can come from only a couple of sources. Either you received it from customers paying you for your sales, or you borrowed it, or you took money out of your savings account. There is no other legal way to get the cash. Unfortunately, cash does not always come into your bank account when you need it to pay bills. Some customers will pay you on time and some will take as long as they can to pay you. Still, each month, you have to pay the phone bill, the gas and electric bill, the insurance premium, taxes, etc. You must manage your cash so you have it when you need it.

The time of the month or year that money comes in varies from type of business to type of business. Your lender or investor wants to know when your cash will most likely come in and when your bills will need to be paid. You show this by preparing the Cash Flow Statement. For example, a Cash Flow Statement will show for each month when you think you will pay your bills and when your income (cash) will come into the business. This is done month-by-month for the first year and annually thereafter for a projection.

The cash flow statement is simple projections of the cash inflows and outflows for a given period of time. It is in a sense what the company checkbook will look like over time. A positive cash flow simply means more cash came in the business than went out in a given period of time. The cash position of a business is the difference between cash inflows and cash outflows for any given period of time without borrowing any short-term loans. Always remember that good collateral doesn't make a bad loan good. Just because a business is profitable does not create the ability for loans to be repaid or investors to be able to draw money out of a business. The understandable factor is that "Cash" is what pays the bills. It is possible to go broke while showing a profit (but just not being able to get your cash) because customers that owe you money simply will not pay their bills. Therefore, in order to successfully borrow money long-term, you will need collateral, profits and "Cash Flow." 


\section{- $\quad$ Application of Funds}

The funding requirements will be an initial amount for operating capital and the purchase of assets to carry out the ideas and sales efforts of your business. In addition, all development cost to develop the services/products and to introduce them into the market will be further cash/investment requirements. The complete summary of your whole funding requirement could be expressed as: (1) all cost to complete development of product/service; (2) all cost to purchase equipment/fixed assets; (3) marketing cost to launch and carry out total marketing strategy; and (4) all working capital cost to open and carry on the business for a period of time according to your cash flow projections. In addition, always explain how any investment or loan proceeds will be used for the above listed four items.

In the "Repayment Proposal," you should define the time required before a payback of principle to lenders and investors can occur. For example, address how much time it will take until investors or banks get paid back in full, and address any financial projections that indicate the loan /investment funds will generate profits eventually and provide cash for a payback to occur. In addition, express the intentions that if extra profits are generated, they will hopefully be utilized to reduce bank debt and extinguish any investor's debt. Financial survival is always the result of continuous management and control, applied according to a good plan.

\section{- $\quad$ Appendix to the Business Plan}

This section is where you put the data which backs up what you have said in your Business Plan. If you are relying on a population survey done by your local Chamber of Commerce, then attach the summary and important parts of that survey to you plan in the Appendix. Always use good exhibits to clearly show how you come up with projections. Include exhibits such as: product literature and brochures, sales sheets, projected customers, customer lists, media coverage in the past as to your products or services, industry publications, any patent information, market research data, photographs, advertising campaign materials, charts, diagrams, maps, and anything else you have which will give a clearer picture of what you have and what you want should be included as attachments or exhibits to the plan.

You should attach resumes of yourself and other key people who will be helping you, as well as each of your advisors (accountant, lawyer, insurance agent, etc.). Also give detailed explanations of any formulas, sampling methods, and other ways of computing market share, etc. that you have referenced in the body of your Business Plan. In additions, place copies of all sales brochures, flyers, handouts, questionnaires, literature you intend to use that will go to the general public. This allows the investor/lender to see what it is first hand that you are discussing in your Business Plan.

Each exhibit should be "tabbed" individually and referenced in the plan as "Exhibit A" "Exhibit B" and so on. Make certain that you show these exhibits in the Table of Contents. You must make it easy for the lender/investor to read. And, equally important, it must be easy for you to read since this business plan is your blueprint for how you will set up and operate your business successfully!

\section{SUMMARY}

As stated previously, the business plan is written to guide the business owner in how to develop and operate the business. A business plan becomes the plan of operating the business. On the other hand, it is written with the intention of attracting a lender or investor to finance the start-up or next phase of the business.

From this perspective, it is important to establish what has been done to date, address what is being done today to lay the groundwork for success, and then discuss what will be done to improve your business in the future. Your business plan should include the following sections: a good business plan includes sections on (1) Title Page, (2) Table of Contents, (3) Executive Summary, (4) Business Description, (5) Management (6) Market and Business Analysis, (7) Business and Market Development, (8) Marketing and Sales, (9) Financial Data, (10) Application of Funds, and (11) an Appendix. 
The business plan is the product of a strategic thinking or planning process. The strategic direction developed in that process can then be communicated in the form of a business plan to lenders, potential investors and associates within your company. The development of a strategic direction is a critical step for your company. It allows your business to leverage the knowledge and competence of its management team, staff and advisors to develop a strategic direction for the organization that will lead to its best chance for success. This gives you an opportunity to use the advising team you have put together.

\section{NOTES}


NOTES 